\title{
Les archives et la documentation en Abitibi-Témiscamingue
}

\section{Louise-Hélène Audet}

Volume 49, 1982

URI : https://id.erudit.org/iderudit/1007092ar

DOI : https://doi.org/10.7202/1007092ar

Aller au sommaire du numéro

Éditeur(s)

Les Éditions Historia Ecclesiæ Catholicæ Canadensis Inc.

ISSN

0318-6172 (imprimé)

1927-7067 (numérique)

Découvrir la revue

Citer cet article

Audet, L.-H. (1982). Les archives et la documentation en Abitibi-Témiscamingue. Sessions d'étude - Société canadienne d'histoire de

l'Église catholique, 49, 69-70. https://doi.org/10.7202/1007092ar

Tous droits réservés (C) Les Éditions Historia Ecclesiæ Catholicæ Canadensis Inc., 1982
Ce document est protégé par la loi sur le droit d'auteur. L'utilisation des services d'Érudit (y compris la reproduction) est assujettie à sa politique d'utilisation que vous pouvez consulter en ligne.

https://apropos.erudit.org/fr/usagers/politique-dutilisation/ 


\section{Les archives et la documentation}

\section{en Abitibi-Témiscamingue}

Dès son implantation dans la région de l'Abitibi-Témiscamingue, l'Université du Québec a favorisé la création d'un Centre de recherche et de documentation régionales. En 1971, le Centre d'études du Nord-Ouest Québécois est mis sur pied avec le mandat précis de conserver les travaux et thèses des étudiants, de recueillir les témoignages de vie des pionniers et aussi de fournir aux chercheurs la documentation pertinente pour alimenter leurs recherches.

Cependant peu à peu un projet plus vaste fait son chemin : celui d'élargir le mandat du C.E.N.O.Q. et d'en faire un centre d'archives qui s'occupera activement de conserver des documents produits par les organismes publics et para-publics, les familles ou les individus. En 1972, le Centre d'archives devient une réalité et s'oriente résolument vers la cueillette de fonds et de collections. Dans le but de mettre en valeur les richesses de cette documentation, l'archiviste, Donat Martineau, organise différentes manifestations culturelles, telles que des expositions, des randonnées de découverte, des causeries ou conférences sur le développement des archives et l'histoire régionale, des lancements, etc. Ainsi le Centre d'archives est devenu un outil pédagogique et didactique au service de l'ensemble des citoyens.

$\mathrm{Au}$ cours des années, les dons ou les prêts de fonds et collections d'archives se succèdent régulièrement et fournissent aux usagers un éventail de plus en plus grand de pièces d'archives sur la colonisation, l'agriculture, les mines, la vie intellectuelle et religieuse, les loisirs, etc.

Parmi nos collaborateurs, il convient de signaler l'évêque de RouynNoranda qui, dès la création du diocèse en 1974, s'est préoccupé de la conservation des archives religieuses. À la suite de la signature d'une convention de prêt, les archives paroissiales, les documents personnels du clergé, les archives administratives telles que les lettres pastorales 
des évêques peuvent être versés au Centre des archives pour le bénéfice des chercheurs. Le diocèse d'Amos a aussi déposé des documents qui retracent l'histoire religieuse de l'Abitibi depuis 1939.

Comme la région du Témiscamingue a été évangélisée par les Missionnaires Oblats de Marie-Immaculée, les documents d'archives qui retracent leurs oeuvres sont une source d'information très riche pour les chercheurs, qu'il s'agisse de photographies, de récits de missionnaires ou encore du fonds d'une institution comme l'école d'agriculture Moffet de Ville-Marie.

Depuis 1979, l'Université a cessé d'opérer le Centre d'archives. Les Archives nationales du Québec, dans le cadre de leur politique de régionalisation ont maintenant pris la relève en ouvrant le Centre régional de l'Abitibi-Témiscamingue à Noranda, pour desservir toute la population. Les objectifs sont les mêmes, c'est-à-dire assurer la conservation, la préservation et la diffusion de notre patrimoine archivistique très riche et original et ainsi susciter la publication d'ouvrages régionaux qui apporteront de nouvelles connaissances sur l'évolution du mode de vie en Abitibi-Témiscamingue.

Le chemin parcouru depuis les dix dernières années nous a permis d'inventorier une grande quantité de documents, grâce à l'étroite collaboration de nos intervenants et aussi grâce à des partenaires dynamiques comme les Sociétés d'histoire. Il nous reste à poursuivre et à consolider. C'est un nouveau défi.

Louise-Hélène AUDET, Archiviste régionale. 